\title{
Less inequality through universal access? Socioeconomic background of tertiary entrants in Australia after the expansion of university participation
}

\author{
Krzysztof Czarnecki $^{1}$ (D)
}

Published online: 20 December 2017

(C) The Author(s) 2017. This article is an open access publication

\begin{abstract}
This article investigates the consequences of an expansion of domestic university places in Australia after 2009 for inequalities in access to tertiary education. I focused on how different individual-level socioeconomic factors were influencing not only the likelihood of continuing education at the tertiary level but also a type of institution one studies at. Thus, I simultaneously analyse vertical and horizontal dimensions of inequalities in access. The expansion has not dramatically changed the differentiated access within different socioeconomic groups. However, the influence of parental education and secondary school context on continuing education has weakened. But those who have benefited the most are young people from upper service class. They not only approach near-universal access faster than other social classes but also improve their relative chances to study at the most prestigious institutions. Controlling for academic ability at the age of 15 showed that socioeconomic background continuous to matter after that age. This means that student-oriented equity policies undertaken closer to the point of transition to tertiary education have a capacity to decrease educational inequalities. Results are discussed against the background of the current higher education policy trends regarding equity in access.
\end{abstract}

Keywords Inequalities in access to higher education · Educational expansion · Social stratification $\cdot$ Australia $\cdot$ Multinomial logistic regression

Electronic supplementary material The online version of this article (https://doi.org/10.1007/s10734-0170222-1) contains supplementary material, which is available to authorized users.

Krzysztof Czarnecki

krzysztof.czarnecki@ue.poznan.pl

1 Department of Labour and Social Policy, Poznan University of Economics and Business, Al.

Niepodległości 10, 61-875 Poznan, Poland 


\section{Introduction}

The main purpose of this article is to assess the hypothesis which can be derived from the theory of "effectively maintained inequalities" (EMI, Lucas 2001) and the recent work of Simon Marginson (2016): as higher education participation expands, there is a tendency for social inequality in distribution of post-secondary educational outcomes to increase. The expansion of university places is claimed to be propitious to the decrease of socioeconomic gradient of participation in any type of undergraduate study, i.e. in vertical inequalities in access to tertiary education ${ }^{1}$ (Breen et al. 2009). But due to the positional character of educational goods and incessant strive of higher social classes for intergenerational status maintenance (see Bills 2016; Breen and Goldthorpe 1997), one should expect a simultaneous, reverse trend in inequalities in access to qualitatively different post-secondary outcomesespecially to elite universities. In other words, horizontal inequalities in education should increase.

Recent developments in Australian university sector offer a good opportunity to test the above-mentioned hypothesis. The country has experienced nearly $30 \%$ growth of domestic enrolment in undergraduate university studies between 2009 and 2015. Previous analyses of horizontal inequalities in Australia took a snapshot of a single cohort and did not consider the developments after the recent expansion. This article aims to fill this gap by using the data from the Longitudinal Surveys of Australian Youth and comparing cohorts which turned 15 years old in 2003, 2006 and 2009. I use multinomial logistic regression models.

Additionally, I ask to what extent the observed effects of socioeconomic backgrounds on the distribution of individuals between (1) elite universities, (2) non-elite universities, (3) nonuniversity tertiary institutions and (4) not participating can be explained by academic ability? For that, I will decompose the socioeconomic background effects into those which can be attributed to academic ability at the age of 15 , and those which cannot. This explanatory endeavour will help formulating policy recommendations as to preferable timing and form of intervention that could weaken inequalities resulting from the role of tertiary education in social stratification.

\section{Background and theory}

In the recent decades, most of the advanced economies have experienced a rapid expansion of participation in tertiary education and, in turn, the proportion of highly educated population. This was expected to enhance intergenerational social mobility by making young people from lower socioeconomic backgrounds more likely to enrol in tertiary studies. Meritocratic societies were assumed, in which educational outcomes are the major requirements for prestigious jobs. The number of unprivileged students has indeed increased in absolute terms, but significant family background-related inequalities still persist (Breen et al. 2009; Jackson 2013).

At the beginning of the twenty-first century, many countries have started to face a slower growth of the number of available professional and managerial jobs for graduates (Wren 2013). This coincided with an ongoing increase of the pool of individuals with tertiary degrees.

\footnotetext{
${ }^{1}$ I consistently use the term "tertiary education" to refer to both universities and non-university tertiary institutions in Australia (technical and further education). "Higher education" will refer to the university sector only.
} 
Since educational credentials are positional goods (see Bills 2016), their value on the labour market depends on the number of competitors possessing similar credentials. Given the labour market and tertiary education dynamics, the relative advantage in competition for occupational status that an average tertiary degree used to secure has decreased, while the cost of not participating has increased (Corak 2012; Bills 2016).

The average return from investment in tertiary education may differentiate (or even decrease at times) in systems where access is mass or universal (in Trow's sense 1973), but graduation from top universities or fields of study still greatly increases individual chances for achieving a more prestigious occupational status or higher income compared to peers with other educational qualifications (van de Werfhorst et al. 2008; Triventi 2013; Rivera 2015). Higher education is a field in which a double competition plays out: between institutions which strive for status, and between students and their families who struggle to obtain credentials and learning outcomes that would help them achieve desired positions in occupational structure (Marginson 2016: p. 127). As Marginson argues, expanding tertiary education systems in which a growing majority of each age cohort study ("high participation systems") tend to become more stratified (vertically stretched) in terms of quality of core activities, prestige and status of graduates of formally or informally differentiated tertiary schools. Stratification of the sector is both supply side- and demand side-driven, and its increase leads to fiercer competition for degrees from those institutions or fields of study which provide better career prospects than other at a given point in time - be that for their symbolic value or for learning outcomes they enable to achieve. In this competition, which magnifies at transition points from one educational level to another, students who are better endowed in cultural, economic and social capital are on a privileged position while their counterparts self-exclude or underinvest (Hart 2012; Jackson 2013).

Therefore, horizontal inequalities in access (Gerber and Cheung 2008)-socioeconomic differences in the likelihood of achieving qualitatively different educational outcomes - rise in prominence when a system is expanding and becoming more stratified. In the sociological literature, this is often associated with the EMI theory (Lucas 2001). Many researchers investigated the phenomenon of prestigious universities and fields of study being continuously dominated by people with higher socioeconomic status (see the literature surveys in Kraaykamp et al. 2013 and Lee 2014). This may not be changing in times of expansion, as newly created university places can be more likely to be taken first by more privileged individuals who would otherwise not study (Jonsson 2014) or study at low-prestige institutions.

To investigate the relative impact of socioeconomic status on distribution of young people across different post-secondary educational outcomes, I decided to draw from the tradition of sociological studies in which family background effects on educational inequalities are decomposed into "primary" and "secondary" effects (Jackson 2013). As Marjoribanks (2005) put it, "primary effects are related to [social] background differences in early school achievement, whereas secondary effects relate to young people's choices as they make educational decisions about their futures". Technically speaking, primary effects are mediated by school performance/academic ability, while secondary effects relate to socioeconomic backgrounds influencing educational destination directly, through mechanisms of choice which are usually unobserved within this research tradition. The assumption that school or academic ability test performance depends largely on family background is well grounded in the literature (Chowdry et al. 2013). Both primary and secondary effects observed at different educational transition points are explained from numerous theoretical perspectives (see Jackson 2013). 
Decomposing socioeconomic background effects into primary and secondary has practical implication. If they can be explained solely by academic ability at certain age, an effective equity-enhancing intervention should rather occur before that age and focus on supporting better school performance of unprivileged students. Some major findings in educational studies (Heckman 2008; Chowdry et al. 2013) suggests that the efficiency of policy interventions aimed at equalizing educational outcomes is greater the earlier an intervention is undertaken. This underpins the rationale for shifting resources from equity policies at later stages of education systems to early-childhood institutions or to improving parenting capabilities in lower-status families. But efficiency of such approaches depends on the structure of educational opportunities later on in the system and the magnitude of secondary effects. Even the most effectively augmented chances and capacities of poor family offspring can be squandered later on if the participation in any further stage largely depends on socioeconomic backgrounds, such as family income (e.g. fees, see Hoxby and Avery 2013), or unfavourable school environment (Hart 2012). Likewise, early-stage interventions can be ineffective if there are supply side constraints, such as very limited places at elite institutions within a highly stratified system (Triventi 2013). I believe that there is a solid case for not neglecting inequalities that arise later on in the system and for attempting to reduce them to a possible minimum.

\section{The Australian context}

Australian tertiary education ${ }^{2}$ is a high participation system, consisting of formally homogeneous universities which issue primarily higher education degrees and the heterogeneous sector of non-university institutions (technical and further education (TAFE)). TAFEs provide vocationally oriented post-compulsory education, but also issue bachelor degrees. Universities operate on a centrally regulated quasi-market and their domestic teaching activity is largely financed from federal sources. They compete for students, whose financial contribution in a form of state-subsidised tuition fees ${ }^{3}$ is fixed (it differs across fields of study but not across universities), which tames the system stratification. However, the hierarchy between institutions is clear and largely path-dependent. There are eight old universities ${ }^{4}$ ("the Group of Eight" coalition, hereafter referred to as "Go8") which clearly stand out in terms of resource endowment, research intensity, size and comprehensive range of qualifications they offer, and ability to select their students. Their special status is underlined in the studies on university segments (Williams 2007; Marginson 2016). Furthermore, the literature on undergraduate early salary premiums on the Australian labour market (Birch et al. 2009; Carroll et al. 2014; Cherastidtham and Norton 2014; Lee 2014) provides positive, although weak, evidence for the advantaged position of elite university graduates in the early stages of professional careers. Considering the representative sample of population aged 25-59, the analysis of the Household, Income and Labour Dynamics in Australia Survey (HILDA) shows that in 2012, the Go8 graduates recorded significantly higher salary premium than the graduates of other, non-technological universities, with some variation related to gender (Wilkins 2015, Table 7.4, p. 97). These gaps

\footnotetext{
${ }^{2}$ A brief introduction into the Australian tertiary education system can be found in the article of Chesters and Watson (2013: pp. 199, 200) and in Chapter 9 of the Marginson's book (2016).

${ }^{3} \mathrm{~A}$ vast majority of students receive income-contingent federal loans that cover tuition costs and are deemed to be neutral for inequalities in access (Marginson 2016: p. 159).

${ }^{4}$ Australian National University, Monash University, University of Adelaide, University of Melbourne, University of New South Wales, University of Queensland, University of Sydney, University of Western Australia.
} 
might be underestimated due to uncontrolled differences in the composition of fields of study and in the graduates' employment status across the university categories (ibid., p. 73).

In 2009, following the prescriptions of the Review of Australian Higher Education: Final Report ("the Bradley review"; Bradley 2008), the Labour Government undertook a course towards transition from mass to universal access to higher education. It endorsed a target of $40 \%$ of 25-34-year-old individuals having at least a bachelor degree by 2025 . This was to be achieved primarily by uncapping the number of state-financed study places that could be offered by universities (and thus creating the quasi-demand-driven system; see Gale 2015). As reported by King and James (2013), enrolments had been increasing in response to the reform already before it was officially implemented in 2012. Larkins (2015) evaluated university enrolment patterns between 2009 and 2013. The growth of enrolments has been lower, at 14.3\%, in Go8, while the total growth rate was $26.6 \%$. Neither was the growth equally distributed among nonelite universities. King and James (2013) point out that it was mostly the non-elite sector in big metropolitan cities that has achieved their preferred enrolment by retaining highly qualified students and increasing the uptake of those with medium-level entrance qualifications. While the university segment was experiencing a steady, fast expansion, the system has become more stratified because of the rise in status of selective institutions (Marginson 2016) and the proportion of new domestic bachelor enrolments at Go8 decreasing from 25.4 to 22.9\% (Larkins 2015). For that, one would particularly expect deterioration in social access to elite universities.

A number of research on inequalities in tertiary education participation in Australia reached conclusions similar to findings in other countries. The earlier sector expansion has not resulted in a significant reduction of class inequalities in educational attainment on the tertiary level (Chesters and Watson 2013; Le et al. 2011). Chesters (2015) found that although that expansion has reduced inequality to some extent, having a university-educated parent still determines the propensity of university graduation. Lee (2014) shows that both parental occupation and education were strong predictors of the attainment of a bachelor's or higher degree before the expansion, and that that individual's family backgrounds significantly predicted the prestige of students' university, but not the field of study. But Gale and Parker (2013) argue that students from low-socioeconomic status families tend to enrol both in some less prestigious fields and in low-status institutions. The type of secondary school attended also matters in Australia (Marjoribanks 2005; Chesters 2015). According to Marginson (2016: p. 151), private secondary schools, attended by approximately $40 \%$ of students, play an important role in reproducing social inequality, as "the leading private schools, which charge high fees and are dominated by affluent families, are effective in placing students in sought-after university courses". Gemici et al. (2013) found the achievement in secondary school to be more important than social class effects at the point of entry to higher education. Similarly, Cardak and Ryan (2009) argue that interventions at the last year of secondary school may not have the intended impact due to the primary importance of previous achievement. Eligible students from low and high socioeconomic backgrounds are equally likely to attend university. However, eligibility itself has the positive socioeconomic gradient. In the context of horizontal inequalities, the key importance of academic ability when the students were in year 9 (15 years old) has been shown by Marks (2013).

\section{Data}

I use the Longitudinal Surveys of Australian Youth (LSAY) of three age cohorts: 2003, 2006 and 2009. The LSAY is a panel, integrated with the OECD's PISA study since 2003. The 
representative samples of secondary school students take part in the internationally standardized assessment of academic ability at the age of 15 and then are surveyed on annual basis (NCVER 2011). ${ }^{5}$ This enables to track educational trajectories of young people while having rich information on their individual and family characteristics at the time of PISA test-taking. ${ }^{6}$ Most respondents would start the undergraduate studies in, respectively, 2006-2007, 20092010 and 2012-2013. ' Therefore, the 2003 cohort represents the "pre-expansion" generation, the 2006 cohort was transiting to tertiary education at the onset of expansion (universities had already started to offer extra places in anticipation of the reform), and the 2009 cohort was commencing studies after the new policy was officially implemented. I restricted the sample to individuals who stayed in the panel until they reached the typical tertiary education eligibility age. To control differences in the sample composition, the follow-up was restricted to seven waves of each survey, which is the number of completed waves in the last one. The final samples seem to represent well the structure of the Australian undergraduate student population $^{8}$ (see descriptive statistics in Tables 1 and 2). Sample size differences result from higher dropout rates in later years of data collection. Out of the commencing sample size, $84 \%$ stayed in the 2003 sample, $59 \%$ in 2006 and $54 \%$ in 2009.

The dependant variable-post-secondary educational outcome-was divided into four categories: (1) not studying, (2) technical and further education (TAFE), (3) all other universities ("other uni's"), and (4) the Group of Eight (Go8). The fourth category is the most diverse one and one might argue that it could be separated into two other (see Lee 2014), e.g. acknowledging the specificity of technological universities. However, as Marginson shows (2016: p. 153), these universities do not stand out from other non-elite universities in research intensity (the main status driver) and student selectivity. ${ }^{9}$ Individuals who did not provide information on the attended tertiary institution in any wave were classified as not studying.

Socioeconomic status is measured by two nominal variables: parental occupation (social class) and parental education. ${ }^{10}$ They are deemed to be empirically and theoretically better proxies of family background than geographical (postcode) measures traditionally used in Australian studies of social inequalities (Lim et al. 2011). Following Erikson (1984), I took the dominance approach, taking the higher class or higher level of education to represent the family status. For parental education, I constructed two categories which reflect the presence of university traditions in a student family: having a higher education diploma, or not. I applied the Erikson-Goldthorpe-

\footnotetext{
${ }^{5}$ The LSAY has quite high attrition rates. Applying regression in the core analysis and the fact that all explanatory variables are observed in the first wave make this problem less aggravate and justifies not applying sample and attrition weights (Lim 2011).

${ }^{6}$ The only variables with missing values were parental education $(2,1.4$ and $1.7 \%$ of the respective cohorts) and occupation $(3.2,1.9$ and $2.8 \%)$. The values were imputed using regression imputation.

${ }^{7}$ In the analysed period students were facing similar macroeconomic conditions since the recent economic crisis left Australia largely unaffected.

${ }^{8}$ Comparing the proportion of female students with official government data (in brackets): $60.3 \%(58.7 \%), 58 \%$ $(56.5 \%)$ and $57.1 \%(56.7 \%)$. Considering gender proportions in the whole samples, non-studying men seem to be a little underrepresented.

${ }^{9}$ There are significant differences between Australian tertiary institutions in a disciplinary structure of the educational offer (Table B in Online Resource 1). Including this dimension in the analysis of horizontal inequalities in access would necessitate a separate paper. Nevertheless, it should be kept in mind that more prestigious universities could be dominated by socially privileged individuals partly because they offer relatively more places in prestigious study programmes such as law or medicine.

${ }^{10}$ Appropriate checks ensured that there are no multicollinearity problems (variance inflation factors were less than 1.5 and condition numbers - 7.5). V-Cramer measures indicate a medium correlation between the variables (0.43 for 2003 and 2006 cohorts, 0.44 for 2009).
} 


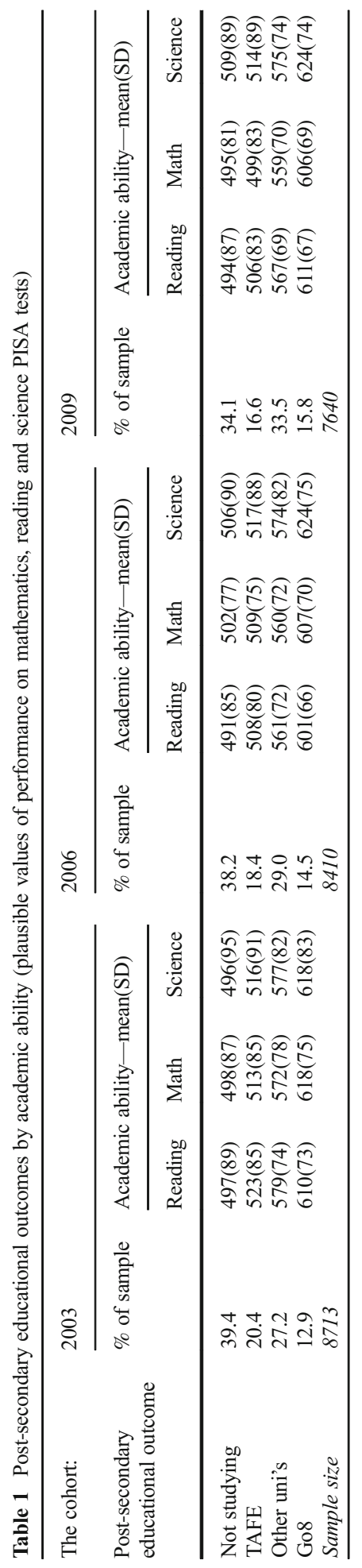


Table 2 Descriptive statistics for the independent variables

\begin{tabular}{|c|c|c|c|}
\hline & \multicolumn{3}{|c|}{ Sample proportion (\%) } \\
\hline & 2003 & 2006 & 2009 \\
\hline \multicolumn{4}{|l|}{ Parental occupation } \\
\hline Working class & 28.3 & 27.4 & 25.6 \\
\hline Lower service class & 22.9 & 20.0 & 22.9 \\
\hline Middle service class & 36.6 & 34.6 & 38.1 \\
\hline Upper service class & 12.2 & 18.0 & 13.4 \\
\hline \multicolumn{4}{|l|}{ Parental education } \\
\hline No university degree & 57.3 & 57.6 & 55.3 \\
\hline University degree & 42.7 & 42.4 & 44.7 \\
\hline \multicolumn{4}{|l|}{ Secondary school } \\
\hline Private & 37.8 & 42.3 & 44.0 \\
\hline Public & 62.2 & 57.7 & 56.0 \\
\hline \multicolumn{4}{|l|}{ Geographical location } \\
\hline Metropolitan & 70.8 & 69.5 & 70.8 \\
\hline Other & 29.2 & 30.5 & 29.2 \\
\hline \multicolumn{4}{|l|}{ Gender } \\
\hline Female & 51.2 & 52.3 & 55.4 \\
\hline Male & 48.8 & 47.7 & 44.6 \\
\hline
\end{tabular}

Portocarero (EGP) classification scheme (Erikson and Goldthorpe 1992) to measure parental class, used its three-class version and then split the highest class into two in order to differentiate between top managers and professionals (doctors, lawyers or architects) and large enterprise owners ("upper service class"), and lower-tier managers, associate professionals and higher sales employees ("middle service class"). The other two classes are "lower service class" (includes routine clerical and sales workers, small entrepreneurs, some skilled service) and "working class" (includes skilled and non-skilled manual workers and farmers, elementary sales and services).

Academic ability is the individual performance on a PISA test. The test is administered to students in the 9th grade (14-15 years old) and results are presented as plausible values of performance - alternative estimates of scores that could have been observed if students were asked to answer all questions. The OECD recommendations (OECD 2009) suggest using the formula (Rubin 1987) including all plausible values in the estimations when the sample size is not large, which is not the case here. Thus, I decided to estimate the model three times, with the first plausible values from each type of test (reading, science and math). The final model estimations are averages from these three estimations.

Type of secondary school attended is represented as a binary variable, distinguishing the impact of usually more prestigious private schools and public ("government", in Australian terms) schools. Since only private schools charge tuition fees, this variable also partly compensates for the lack of information on family financial resources. Australian students take up the PISA test during the second or third grade of secondary school, so it is safe to assume that a type of secondary school attended influences both performance on the PISA test and post-secondary educational outcomes.

Finally, I include information on gender of the respondents and a geographical location of their secondary school, distinguishing between metropolitan (over 100,000 inhabitants) and other areas. The location, related closely to a place of living, should be expected to influence the outcome because of large distances in Australia and concentration of universities (especially Go8) in the highly populated metropolises. Potential barriers related to non-English speaking background could not be accounted for because of low sample proportions (8-9\%). 
Table A (see Online Resource 1) shows the distribution of individuals from different socioeconomic backgrounds between the categories of the outcome variable. It can give a glimpse of scope of inequalities under question. Go8 is dominated by students from middleand upper-service class families. Only 5-7\% of individuals from working class studied there, and roughly a half did not continue education. A moderate move away from TAFEs to nonelite universities, and to Go8 in case of lower and upper service class, is an apparent change. Distribution of students with no parent with a university degree is also strikingly skewed towards better educational options. Individuals are unequally distributed also according to gender, type of secondary school attended and its geographical location. Cross tables are not very helpful if one wants to analyse change across the cohorts or the predictive strength of socioeconomic factors while controlling for differences in academic ability. For this, we turn to the results of regression analysis.

\section{Method}

To account for the nominal character of the outcome variable, I used multinomial logistic regression (MLR). To estimate coefficients, I applied the Karlson-Holm-Breen $(k h b)$ method (Kohler et al. 2011; Breen et al. 2013). $k h b$ allows one to conduct a path analysis in non-linear probability models and hence, to decompose the total effects of independent variables into direct effects and indirect effects. In the model, independent variables (parental occupation and education, type of secondary school and its geographical location, gender) determine academic ability (mediator variable), which in turn influences the post-secondary educational pathways of individuals. This link is called "the primary effect" in the above-mentioned sociological tradition. The direct effect of independent variables on the outcome variable ("the secondary effect") occurs once academic ability is controlled for. Applying this method allows me to assess to what extent socioeconomic characteristics of individuals determine post-secondary educational outcomes irrespective of academic ability at the age of 15. Formally,

$$
\begin{aligned}
\ln \frac{\operatorname{Pr}\left(y=m \mid x_{i}\right)}{\operatorname{Pr}\left(y=b \mid x_{i}\right)}= & \beta_{0, m \mid b}+\beta_{1, m \mid b} \text { lsc }+\beta_{2, m \mid b} \text { msc }+\beta_{3, m \mid b} \text { hsc }+\beta_{4, m \mid b} \text { uni }+\beta_{5, m \mid b} \text { male } \\
& +\beta_{6, m \mid b} \text { nom }+\beta_{7, m \mid b} \text { pub }+\gamma_{8, m \mid b} \text { abi }+\epsilon
\end{aligned}
$$

where $b$ represents the baseline category and $m$ a second category from each set of binary logits among all pairs of outcomes, lsc-lower-service class category, msc-middle service class, hsc - higher service class (working class is a reference category), uni-having a highly educated parent, male - gender, nom - a non-metropolitan location of school, pub - attending a public secondary school, abi-academic ability (continuous variable), and $\epsilon$-error term. This is the full model (the model with a mediator: $\gamma_{8, m \mid b}$ abi). The $k h b$ method extracts from abi (the mediator) the information that is not contained in each of previous variables $\left(X_{k}\right)$ by calculating the residuals $(R)$ of a linear regression of abi on $X_{k}$ :

$$
R=\operatorname{abi}-\left(a+b X_{k}\right) .
$$

$R$ is then used instead of abi for the reduced model (for further explanation, see Kohler et al. 2011: pp. 423, 424). The measure of the degree to which abi mediates the abi- $\ln \frac{\operatorname{Pr}\left(y=m \mid x_{i}\right)}{\operatorname{Pr}\left(y=b \mid x_{i}\right)}$ 
relationship is called the confounding percentage. Due to length and complexity of the estimation output, I show (Table 3) only the confounding percentages for each variable in each binary logits of the MLR (Eq. 1). Estimated odds ratios and standard errors can be found in Online Resource 1 (Table C). Since odds ratios are not standardized coefficients, comparing them across models or samples is not recommended (Mood 2010) and therefore, inappropriate for the purposes of this study. Instead, I use average partial effects (APE). Partial (marginal) effect is the change in the probability of $m$ (an outcome category) for a change in $x_{k}$ from the start value to the end value (for example from 0 to 1 in case of dummy variables), holding other $x$ 's constant. Average partial effect is the mean of the marginal effect calculated the observed values for all observations in the estimation sample. APE calculations are presented in Fig. 1 and in Online Resource 1 (Table D).

I confirmed that the outcome categories are distinguishable by running the Wald tests for combining alternatives. For robustness checks, I run another MLR models with academic ability as one of the independent variables, and models only with socioeconomic status variables (parental occupation and education) and academic ability as the control. Results were not substantially different from the ones presented below. Using conditional logit or nested logit to explore the effects on any attendance first, and then to examine the choice of tertiary institution would be theoretically justified only with data on school performance at the transition point, and these are missing in the datasets.

\section{Results}

\section{Have inequalities in access to tertiary education changed after the expansion?}

To answer this question, I looked at the changes of APE of each socioeconomic factor on the post-secondary educational outcomes (Fig. 1, solid lines). In the case of parental education, the differences in probabilities of not participating in any tertiary education have decreased between the 2003 and 2009 cohorts by only 2.2 percentage points (p.p.). Similar in direction, but even weaker trend, can be observed for the probability of enrolling in non-elite universities. ${ }^{11}$ Places at low-prestige TAFEs have become more likely to be taken by students without parents with a degree, but the observed change was small. On average, the probability of commencing at elite universities has risen slightly from an increase by 10.4 p.p. (for 2003 cohort) to 11.7 p.p. (for 2009 cohort) for a change of value of the parental education variable, once other independent variables are controlled for.

Differences between lower- or middle-service class and working-class children (Fig. 1(b, c)) were relatively small and have not changed much in the course of the expansion, with one exception. In the 2003 cohort, the average probability of enrolling in Go8 was increasing by 2.6 p.p. for students with lower-service class backgrounds as opposed to those from working class. That value has increased to 4.1 p.p. in the 2009 cohort. Upper-service class children (Fig. 1(d)) are not only more likely to study but also much more likely to study at universities. Their relative position in competition for educational credentials has improved after the expansion, making them the biggest beneficiary of the reform. On average, belonging to upper social class (as opposed to working class) decreased the probability of not studying by

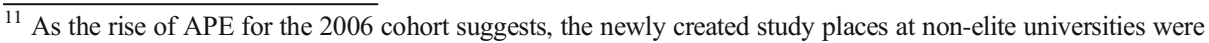
probably first taken by young people from more educated families.
} 
15.3 p.p., a change by 6.1 p.p. in comparison to the pre-expansion age cohort. At the same time, the probability of enrolling in Go8 has risen by 4.6 to 14 p.p. for the 2009 age cohort. Furthermore, their probability of enrolling in TAFEs has simultaneously decreased marginally, while their advantaged position in competition for non-elite universities remained stable after some friction in the 2006 cohort.

Controlling for other factors, private secondary schools are indeed more successful in placing their pupils in universities - more so in non-elite than elite ones (Fig. 1(g)). Yet, their effects have slightly weakened and should not be considered as substantial. Most importantly, there was a decrease in probability (from 12.3 to 6.9 p.p.) of continuing education at tertiary level. On the other hand, public secondary school students have become slightly more likely to study at TAFEs than their peers from private schools.

As expected, also, geography plays its role in distributing students across different postsecondary pathways (Fig. 1(f)). Controlling for other factors, attending a school situated in a metropolitan instead of other area increases the probability of enrolling in Go8 on average by 7.7 p.p. for the 2009 cohort, a rise from 5.9 p.p. at the time before the expansion. But vertical inequalities have decreased, and access to other universities has not been affected by a secondary school location.

Being a male (Fig. 1(e)), unsurprisingly, lowers the probability of continuing education (to a decreasing extent due to expansion). Gender differences for the benefit of women were also substantial in regard to access to non-elite universities, otherwise significant, but negligible. They might be related though to differences in the composition of fields of study on offer at different types of tertiary institutions (see Table B in Online Resource 1).

Access to tertiary schooling remains determined by socioeconomic status, a secondary school attended and gender. Before the expansion, parental education was the strongest predictor of studying at Go8, but then it was overtaken by upper-service class origins. Geographical location and a type of secondary school attended have been consistently less relevant. The upper-service class background has also become the strongest predictor for the probability of continuing education, with other variables losing slightly their importance. Individuals from private secondary schools, highly educated families, middle- or upper-class backgrounds and males are all more likely to enrol in non-elite universities, with each variable having similar predictive power for that outcome. Enrolling in TAFEs can be best predicted by parental education, upper-class background and a type of secondary school attended.

\section{To what extent the effects of socioeconomic factors can be explained by academic ability?}

Adding the academic ability variable to the model substantially increased the proportion of variance explained: from pseudo- $R^{2}$ of 0.07 to 0.14 ( 0.13 for the 2003 cohort). The estimations of MLR models with academic ability as one of the independent variables ${ }^{12}$ showed that this variable has by far superior importance in determining future educational trajectories, although it does not render the effects of other variables insignificant. However, the theoretical purpose is to see to what extent the effects of socioeconomic factors are mediated by academic ability, and not to what extent the latter predicts the outcome by itself. ${ }^{13}$ Hence, we will now take a

\footnotetext{
${ }^{12}$ Results available on request.

${ }^{13}$ Besides, this would entail a contentious theoretical assumption given the impossibility of isolating the impact of the environment from the impact of individual intellectual capacities (Heckman 2008; Fishkin 2014).
} 
a) Parental education - higher (other than higher as a reference category)

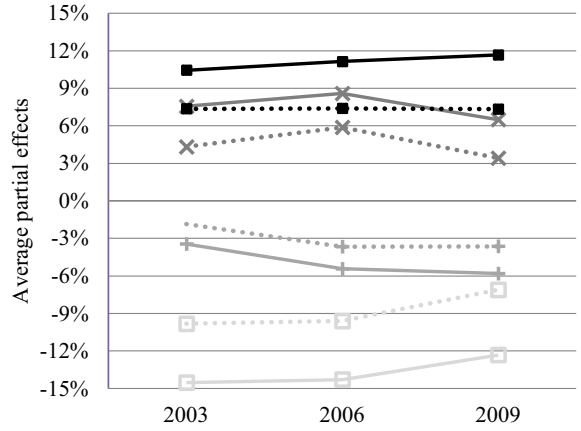

b) Parental occupation - lower service class (ref. working class)

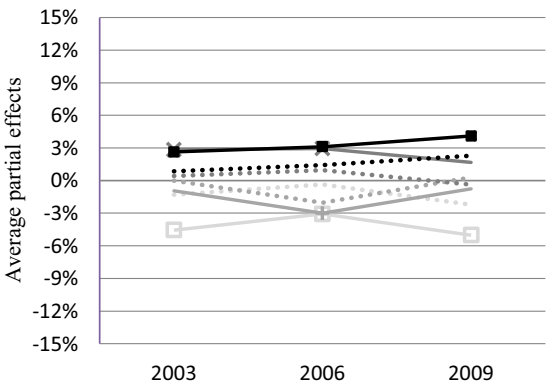

d) Parental occupation - upper service class (ref working class)

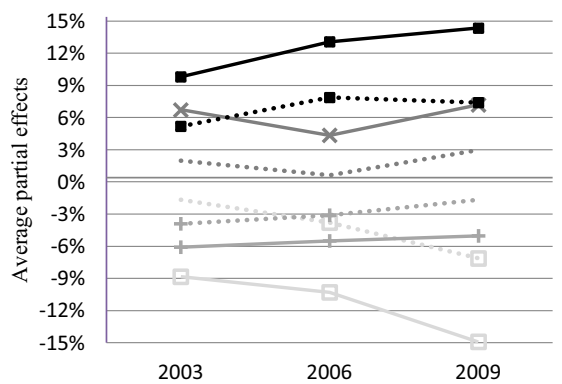

f) Metropolitan secondary school location (ref. other)

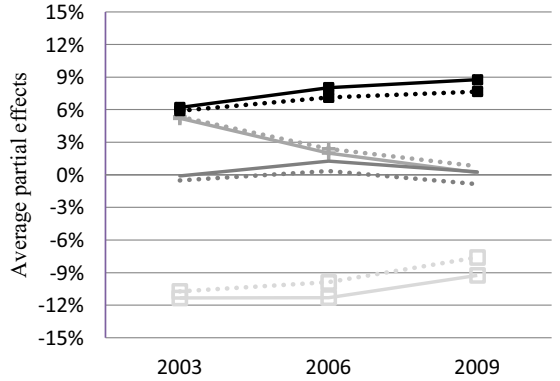

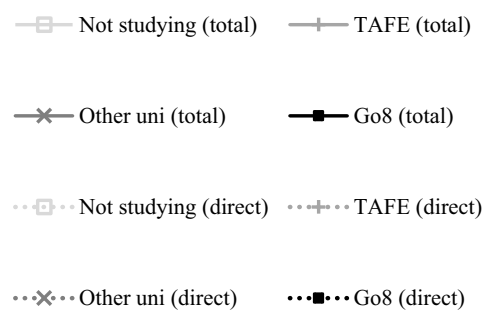

c) Parental occupation- middle service class (ref. working class)

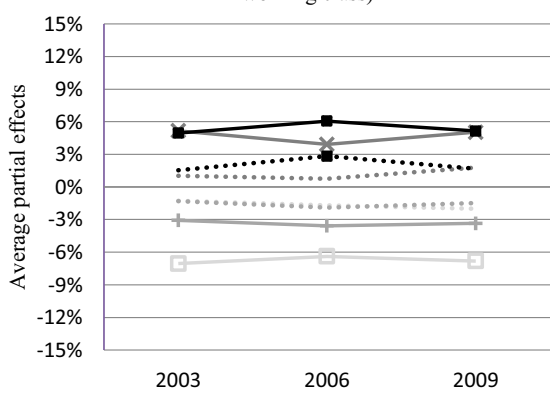

e) Gender - male (ref. female)

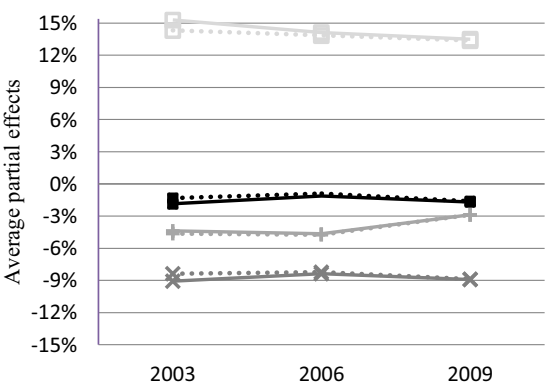

g) Private secondary school (ref. public)

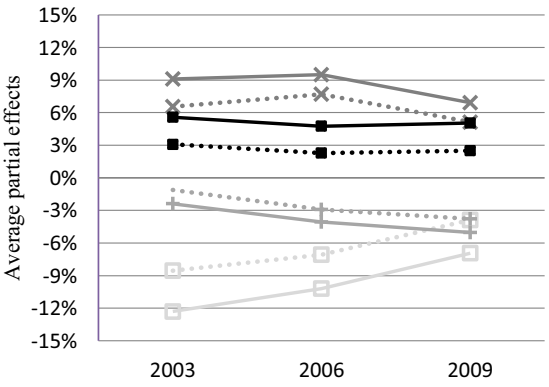


Fig. 1 Average partial effects of socioeconomic factors on probability of four post-secondary educational outcomes.

Note: Average partial effect is an effect size that is an estimate of a population-averaged marginal effect (a change of probability of an outcome category for a change of value of an independent variable - from 0 to 1 in case of dummy variables). ${ }^{\text {a }}$ Total effects, showing differences between categories of a given variable, are represented by solid lines. Dot lines show the effects once academic ability is allowed to confound the relationship between socioeconomic factors and post-secondary destinations (the direct/secondary effects). ${ }^{\mathrm{b}}$ Years indicate the LSAY cohorts. ${ }^{\mathrm{c}}$ For metropolitan location, a city of less than 100,000 inhabitants is the reference category. All the chosen reference categories are supposed to represent unprivileged groups. ${ }^{\mathrm{d}}$ Rectangles and cross-marks represent statistical significance at $p<0.05$ level. Exact values can be found in Table D in Online Resource 1 .

${ }^{\mathrm{e}}$ Pseudo- $R^{2}=0.13$ for the 2003 model, 0.14 for the other

look at the indirect effects (distance between solid and dot lines in Fig. 1) and differences between each pair of outcome categories in the odds ratio estimations obtained from the $\mathrm{khb}$ model (Table 3). This will allow us to see to what extent the effects were mediated by academic ability in different parts of the tertiary sector.

Parental education was influencing the distribution of individuals across all pairs of outcomes, with one exception. The recent surge of university student numbers can be associated with the disappearance of parental education effects on the likelihood of studying at TAFEs instead of not participating in tertiary education. Otherwise, after accounting for the confounding effect of academic ability, parental education effects remain significant, indicating

Table 3 Percentage of social background effects on post-secondary outcomes mediated by academic ability ("confounding percentage")

\begin{tabular}{|c|c|c|c|c|c|c|c|}
\hline Outcome & $\begin{array}{l}\text { Parental } \\
\text { education } \\
\text { (higher) }\end{array}$ & $\begin{array}{l}\text { Lower } \\
\text { service } \\
\text { class }\end{array}$ & $\begin{array}{l}\text { Middle } \\
\text { service } \\
\text { class }\end{array}$ & $\begin{array}{l}\text { Upper } \\
\text { service } \\
\text { class }\end{array}$ & Male & $\begin{array}{l}\text { Non- } \\
\text { metropolitan }\end{array}$ & $\begin{array}{l}\text { Public } \\
\text { school }\end{array}$ \\
\hline \multicolumn{8}{|l|}{ TAFE vs. not studying } \\
\hline $\begin{array}{l}2003 \text { Confounding percentage } \\
2006 \quad(\%)\end{array}$ & 25.2 & & & & & & 21.9 \\
\hline & \multicolumn{3}{|c|}{ Other uni's vs. not studying } & & & & \\
\hline 2003 Confounding percentage & 35.4 & $76.5^{ \pm}$ & $79.0^{ \pm}$ & $70.8^{ \pm}$ & & & 30.3 \\
\hline $2006 \quad(\%)$ & 32.0 & $72.0^{ \pm}$ & $71.7^{ \pm}$ & 63.5 & 2.1 & & 26.1 \\
\hline 2009 & 42.2 & $67.7^{ \pm}$ & $66.7^{ \pm}$ & 53.3 & 0.4 & & 35.9 \\
\hline \multicolumn{8}{|l|}{ Go8 vs. not studying } \\
\hline 2003 Confounding percentage & 30.4 & $71.6^{ \pm}$ & 73.7 & 57.2 & & & 37.4 \\
\hline $2006 \quad(\%)$ & 32.6 & $64.0^{ \pm}$ & 60.2 & 46.8 & 4.1 & & 39.9 \\
\hline 2009 & 38.3 & 52.8 & 68.4 & 50.2 & -0.2 & & 45.3 \\
\hline \multicolumn{8}{|l|}{ Other uni's vs. TAFE } \\
\hline 2003 Confounding percentage & 40.3 & $85.2^{ \pm}$ & $70.8^{ \pm}$ & 51.5 & & & 34.2 \\
\hline $2006 \quad(\%)$ & 31.5 & $47.6^{ \pm}$ & $60.3^{ \pm}$ & 53.7 & & & 24.5 \\
\hline 2009 & 39.9 & & $60.3^{ \pm}$ & 58.5 & 0.2 & & 27.6 \\
\hline \multicolumn{8}{|l|}{ Go8 vs. TAFE } \\
\hline 2003 Confounding percentage & 31.6 & $74.9^{ \pm}$ & 68.5 & 47.2 & & & 42.7 \\
\hline $2006 \quad(\%)$ & 32.5 & $51.5^{ \pm}$ & 54.8 & 42.7 & & & 40.2 \\
\hline 2009 & 37.0 & $59.8^{ \pm}$ & 64.8 & 52.3 & & & 38.3 \\
\hline \multicolumn{8}{|l|}{ Go8 vs. other uni's } \\
\hline 2003 Confounding percentage & 24.2 & & $65.5^{ \pm}$ & 42.3 & & & $65.1^{ \pm}$ \\
\hline 2006 & 33.5 & & 50.0 & 35.2 & & & \\
\hline 2009 & 34.3 & $41.2^{ \pm}$ & $70.7^{ \pm}$ & 46.6 & & & $68.0^{ \pm}$ \\
\hline
\end{tabular}

“ะ” indicates full mediation (the direct effect of an independent variable made insignificant). Empty cells indicate statistical insignificance $(p<0.05$ level) of total or indirect effects. Years, outcome and reference categories like in Fig. 1 
a presence of secondary effects. The confounding ratios vary between 24.2 and $42.2 \%$ across different alternatives, which means that around two thirds of the total effect of parental education cannot be explained by academic ability at the age of 15 . Mediation has become stronger over time when access to Go8 is considered, which means that highly educated parents have become a slightly more successful in ensuring that their children outperform others already at earlier stages of schooling.

There have not been any class effects on the likelihood of studying at TAFEs as opposed to not participating in any tertiary education. However, class effects are apparent when one looks at other alternatives. All advantages from being from lower service class rather than working class result from being more likely to perform well in school. This may be changing though, as academic ability has been explaining less of the total effect in the course of expansion. Moreover, lower-service class children have become even more likely than their working class peers to study at Go8 instead of other universities. The opposite is the case for the non-elite university-TAFE alternative. This suggests that creating extra places at universities had triggered movement across the whole system - it helped lower service class to find their way to elite universities and allowed working class to take up the places abandoned at other universities.

The positional advantage of the middle service class has not been affected. The total effects of such family background on the probability of achieving different post-secondary outcomes are fully mediated by academic ability. However, Table 3 shows that the strength of this mediation has decreased across all alternative outcomes apart from the distribution between universities. Moreover, secondary effects appear once the likelihood of enrolling in Go8 is compared with TAFEs and "not studying" options. This could mean that some young people from lower classes who had a potential to start prestigious studies might drop out entirely from competition in the last years of secondary school due to lack of support. In this context, mechanisms unrelated to academic ability were responsible for around one third of the total effect.

Neither has the expansion changed much with regard to the advantageous position of upper service class. The significance of secondary effects remained in almost all binary outcomes. They account for more less $50 \%$ of the total effects, but with some interesting variation. The probability of studying anywhere could be attributed to academic ability to a decreasing extent across time. Parents with high occupational status increasingly secure their children tertiary education through means other than nurturing their academic ability. But reverse is the case for access to Go8 and the probability of studying at non-elite universities instead of TAFEs.

All differences related to gender and the geographical location of secondary school occur irrespectively of one's academic ability. Private schools seemed to encourage their pupils to continue education more than public schools. The secondary effect of the type of secondary school has decreased slightly, but still remained large-55-65\%. It is even higher (and increasing) for alternatives involving TAFEs and universities. Possibly, private secondary schools were becoming even more successful in making their students realize the qualitative difference between studying at TAFEs and studying at universities. Importantly, any effects of private schools on probability of enrolling in an elite instead of a non-elite university are probably due to their capacity to select more able students or due to better teaching.

\section{Conclusion}

Expanding enrolments and increasing stratification of tertiary education are deemed to be conducive to increasing (horizontal) inequalities in access to prestigious tertiary institutions 
(Triventi 2013; Marginson 2016). The significant rise in number of undergraduate university places in Australia after 2009 allowed me to verify this in a contemporary context, while investigating at the same time to what extent (vertical) inequalities in access to any tertiary education have changed.

The hypothesis that as participation expands there is a tendency for social inequality in distribution of post-secondary educational outcomes to increase is generally supported, but with a necessary caveat that it depends on a dimension of access and a socioeconomic factor one looks at. I found that vertical inequalities have decreased with respect to parental education, a type of secondary school (private or public) and its geographical location. On the other hand, the participation chances of the upper-service class children have substantially increased, and the lower- and the middle-service class children have maintained their advantage against the working class. Continuously, participation is partly determined by socioeconomic status, a type of secondary school one attends and gender.

In terms of horizontal dimension of access, differences in probability of enrolling in a nonelite university have decreased only, and not substantially, between individuals with highly educated parents and their counterparts, and between private and public secondary school students. But regarding elite universities (the Group of Eight), the socioeconomic differences in probability of enrolment either have remained stable or have risen. Individuals with at least one highly educated parent, or coming from lower service class or (in particular) upper service class, or attending a secondary school in the metropolitan area have become even more likely to study at the most prestigious institutions than it was the case before the expansion. At the same time, those with more educated family background or attending private secondary schools have started to be effectively discouraged to enrol in the non-university tertiary sector (TAFE). The expansion has made an average diploma less of a distinctive attribute on the labour market, prompting privileged socioeconomic groups to ensure that their children will study at elite universities.

The other question I sought to answer relates to the extent to which the observed inequalities in access can be explained by higher academic ability of young people from privileged backgrounds. In general, the effects of having lower- or middle-service class background turn statistically insignificant after academic ability is controlled for, suggesting that the origins of these (in any case-small) class inequalities in access should be rather tracked back to early schooling. But the upper-service class position is distinct. They find their way to more prestigious universities through better academic ability of their offspring, but still also through other mechanisms (unobserved with the data). Similar applies to the advantage from having a highly educated parent, as well as from attending a secondary school situated in a metropolitan area or a private one.

Comparing the strength of different factors once academic ability is controlled for, it appears that before the expansion, parental education was the strongest predictor of enrolling at elite university. While its effects remained stable afterwards, coming from upper class and studying in a metropolitan secondary school became similarly important to having a highly educated parent. It mattered relatively less whether a student attended public or private secondary school. However, this used to relatively strongly affect the probability of commencing any studies - but only before the expansion. Later, a secondary school context started losing its importance, while upper class background became a significant factor-eventually as important one as parental education and the school's geographical location. The findings about the direct effects of social background are of 
practical relevance as they suggest a type and timing of equity intervention (Jackson 2013).

The secondary effects (socioeconomic factors significantly affect destinations even when the mediating effect of academic ability is controlled for) appear to be substantial in this study and suggest a rationale for a targeted support also in the final years of secondary schooling, especially to make unprivileged more likely to finish the 12 th grade (the university eligibility criterion). It could be the case that highly educated parents of able pupils better recognize the benefits related to studying at more prestigious tertiary institutions (in terms of future occupational status or income) and encourage their offspring accordingly. The influence of private secondary schools can process in a similar fashion. Thus, more and better intervention is needed to raise the "navigational capacity" (Gale 2015: 269) of high school students coming from families with no university history, and in particular of those who attend public/government schools. It has to be kept in mind, though, that inequalities in access (especially those related to social class) result predominantly from the relatively lower academic ability of unprivileged young people at the age of 15 . This would mean that equity policy should primarily focus on the period preceding the 9th grade. But on the other hand, differences in grades may be relatively more difficult to change since they are rooted in family processes in early childhood and in genetic mechanisms (Jonsson 2014).

More research is needed that would link different tertiary credentials with graduate labour market destinations from a dynamic perspective, accounting for the changes in higher education stratification and diversification (see Lee 2014). Besides, only inequalities in access were studied. Socioeconomic status differences could be further aggravated by a higher propensity of dropout among unprivileged young people, or weakened by possibilities to study for a master degree at another, more prestigious university.

Increased absolute participation of "equity groups", while certainly positive because of potential non-monetary benefits, may not change their relative advantage in positional competition for occupational status. As this study proves, more privileged individuals are more likely to be first to take the places newly created at elite universities. Furthermore, expansion will not lead by itself to equalization of career opportunities unless newcomers from unprivileged backgrounds have similar access not only to the currently most valuable degrees but also social networks embedded in academic and professional communities (Fishkin 2014). Educational qualifications are positional goods, which means that qualification systems adapt to the interests of the dominating classes (Bourdieu and Passeron 1990). Thus, a condition of success of equity interventions is that the number of sought-upon graduate jobs keeps up with the increase of graduation rates. Probably, more effective reforms aiming for reduction of educational inequalities would involve changes on the supply side of tertiary education. These might include (a) reversing the trend towards further polarization of tertiary institutions in terms of prestige, resource endowment and geographical location; (b) rethinking admission criteria in a way that would enable lower-performing high school graduates who are highly motivated or who expose skills unrecognized by school to enrol at more prestigious institutions; (c) improving the mobility of students from TAFEs to university and within the university sector-elite universities should not be able to favour their own undergraduates in the postgraduate recruitment process; and (d) imposing regulations on job requirements that would reduce employers' possibilities to filter out candidates with "lower quality" tertiary education diploma. 
Acknowledgements The study was conducted during the author's research stay at the Melbourne Centre for the Study of Higher Education, University of Melbourne, as a part of the Endeavour Research Fellowship 2015 programme of the Australian government. The author would like to thank Peter James Bentley, David Carroll, Richard James and Ryan Naylor for their support and helpful advice.

\section{Compliance with ethical standards}

Conflict of interest The author declares that he has no conflict of interest.

Open Access This article is distributed under the terms of the Creative Commons Attribution 4.0 International License (http://creativecommons.org/licenses/by/4.0/), which permits unrestricted use, distribution, and reproduction in any medium, provided you give appropriate credit to the original author(s) and the source, provide a link to the Creative Commons license, and indicate if changes were made.

\section{References}

Bills, D. B. (2016). Congested credentials: the material and positional economies of schooling. Research in Social Stratification and Mobility, 43, 65-70.

Birch, E. R., Li, I., \& Miller, P. W. (2009). The influences of institution attended and field of study on graduates' starting salaries. Australian Economic Review, 42(1), 42-63.

Bourdieu, P. \& Passeron, J.-C. (1990). Reproduction in education, society, and culture. Sage Publications.

Bradley, D. (2008). Review of Australian higher education: final report. Canberra: Department of Education, Employment and Workplace Relations.

Breen, R., \& Goldthorpe, J. H. (1997). Explaining educational differentials: towards a formal rational action theory. Rationality and Society, 9(3), 275-305.

Breen, R., Karlson, K. B., \& Holm, A. (2013). Total, direct, and indirect effects in logit and probit models. Sociological Methods \& Research. https://doi.org/10.1177/0049124113494572.

Breen, R., Luijkx, R., Müller, W., \& Pollak, R. (2009). Nonpersistent inequality in educational attainment: evidence from eight European countries. American Journal of Sociology. https://doi.org/10.1086/595951.

Cardak, B. A., \& Ryan, C. (2009). Participation in higher education in Australia: equity and access. Economic Record. https://doi.org/10.1111/j.1475-4932.2009.00570.x.

Carroll, D., Heaton, C. \& Tani, M. (2014). Returns to university quality in Australia: a two-stage analysis. IZA DP, No. 8473 .

Cherastidtham, I. \& Norton, A. (2014). Effects of university prestige and courses on graduates' earnings. Grattan Institute.

Chesters, J. (2015). Maintaining inequality despite expansion: evidence of the link between parents' education and qualitative differences in educational attainment. Higher Education Quarterly, 69(2), 138-157.

Chesters, J., \& Watson, L. (2013). Understanding the persistence of inequality in higher education: evidence from Australia. Journal of Education Policy. https://doi.org/10.1080/02680939.2012.694481.

Chowdry, H., Crawford, C., Dearden, L., Goodman, A., \& Vignoles, A. (2013). Widening participation in higher education: analysis using linked administrative data. Journal of the Royal Statistical Society, $176(2), 431-457$.

Corak, M. (2012). Inequality from generation to generation: the United States in comparison. Graduate School of Public and International Affairs, University of Ottawa, Canada.

Erikson, R. (1984). Social class of men, women and families. Sociology, 18(4), 500-514.

Erikson, R. \& Goldthorpe, J. H. (1992). The constant flux. a study of class mobility in industrial societies. Oxford University Press.

Fishkin, J. (2014). Bottlenecks: a new theory of equal opportunity. Oxford University Press.

Gale, T. (2015). Widening and expanding participation in Australian higher education: in the absence of sociological imagination. Australian Educational Researcher, 42(2), 257-271.

Gale, T. \& Parker, S. (2013). Widening participation in Australian higher education. Report to the Higher Education Funding Council for England (HEFCE) and the Office of Fair Access (OFFA), England.

Gemici, S., Lim, P., \& Karmel, T. (2013). The impact of schools on young people's transition to university. Adelaide: NCVER.

Gerber, T. P., \& Cheung, S. Y. (2008). Horizontal stratification in postsecondary education: forms, explanations and implications. Annual Review of Sociology, 34, 299-318. 
Hart, C. S. (2012). Aspirations, education and social justice: applying Sen and Bourdieu. Bloomsbury Academic.

Heckman, J. J. (2008). Schools, skills, and synapses. Economic Inquiry. https://doi.org/10.1111/j.14657295.2008.00163.x.

Hoxby, C. \& Avery, C. (2013). The missing "one-offs": the hidden supply of high-achieving, low-income students. Brookings papers on economic activity, Spring 2013.

Jackson, M. (Ed.). (2013). Determined to succeed?: performance versus choice in educational attainment. Stanford: Stanford University Press.

Jonsson, J. O. (2014). Ever-expanding university? Social and ethnic inequality in education. In: P. Matteo (Ed.), University adaptation in difficult economic times. Oxford University Press.

King, C. \& James, R. (2013). Creating a demand-driven system. In: S. Marginson (Ed.), Tertiary education policy in Australia (pp. 11-20). Centre for the Study of Higher Education, University of Melbourne.

Kohler, U., Karlson, K. B., \& Holm, A. (2011). Comparing coefficients of nested nonlinear probability models. Stata Journal, 11(3), 420-438.

Kraaykamp, G., Tolsma, J., \& Wolbers, M. H. J. (2013). Educational expansion and field of study: trends in the intergenerational transmission of educational inequality in the Netherlands. British Journal of Sociology of Education. https://doi.org/10.1080/01425692.2013.816622.

Larkins, F. P. (2015). Trends in student enrolments for Australian bachelor degrees: is the present growth strategy sustainable?. LH Martin Institute, The University of Melbourne, Australia.

Le, A. T., Miller, P. W., Slutske, W. S., \& Martin, N. G. (2011). Opportunity and educational outcomes in Australia. Economic Record. https://doi.org/10.1111/j.1475-4932.2011.00749.x.

Lee, J.-S. (2014). The attainability of university degrees and their labour market benefits for young Australians. Higher Education. https://doi.org/10.1007/s10734-014-9722-4.

Lim, P. (2011). Weighting the LSAY programme of international student assessment cohorts. Adelaide: NCVER.

Lim, P., Gemici, S., Rice, J., \& Karmel, T. (2011). Socioeconomic status and the allocation of government resources in Australia: how well do geographic measures perform? Education + Training, 53(7), 570-586.

Lucas, S. R. (2001). Effectively maintained inequality: education transitions, track mobility, and social background effects. American Journal of Sociology, 106(6), 1642-1690.

Marginson, S. (2016). Higher education and the common good. Melbourne University Press.

Marjoribanks, K. (2005). Family background, academic achievement, and educational aspirations as predictors of Australian young adults' educational attainment. Psychological Reports, 96(3), 751-754.

Marks, G. N. (2013). Evaluating effectively maintained inequality: school and post-school transitions, socioeconomic background, academic ability and curricular placement. Social Science Research. https://doi. org/10.1016/j.ssresearch.2013.07.004.

Mood, C. (2010). Logistic regression: why we cannot do what we think we can do, and what we can do about it. European Sociological Review, 26, 67-82.

NCVER (2011). Longitudinal Surveys of Australian Youth (LSAY) 2006 cohort: user guide. Technical report 55, NCVER, Adelaide.

OECD (2009). PISA data analysis manual. OECD Publishing.

Rivera, L. A. (2015).Pedigree: how elite students get elite jobs. Princeton University Press.

Rubin, D. B. (1987). Multiple imputation for nonresponse in surveys. New York: John Wiley \& Sons.

Triventi, M. (2013). Stratification in higher education and its relationship with social inequality: a comparative study of 11 European countries. European Sociological Review. https://doi.org/10.1093/esr/jcr092.

Trow, M. (1973). Problems in the transition from elite to mass higher education. Berkeley: Carnegie Commission on Higher Education.

van de Werfhorst, H. G., Jackson, M., Luijkx, R., \& Vallet, L. A. (2008). Educational fields of study and the intergenerational mobility process in comparative perspective. International Journal of Comparative Sociology, 49(4-5), 369-388.

Wilkins, R. (2015). The household, income and labour dynamics in Australia survey: selected findings from waves 1 to 12. Melbourne Institute of Applied Economic and Social Research, University of Melbourne.

Williams, R. (2007). Ranking Australian universities: controlling for scope. Melbourne: Melbourne Institute of Applied Economic and Social Research.

Wren, A. (Ed.) (2013). The political economy of the service transition. Oxford University Press. 